\title{
Phase Transformations and Microstructural Evolution: Part I
}

\author{
AMY J. CLARKE ${ }^{1,2}$ \\ 1.-Los Alamos National Laboratory, Los Alamos, NM, USA. 2.-e-mail: aclarke@lanl.gov
}

The activities of the Phase Transformations Committee of the Materials Processing \& Manufacturing Division (MPMD) of The Minerals, Metals $\&$ Materials Society (TMS) are oriented toward understanding the fundamental aspects of phase transformations. Emphasis is placed on the thermodynamic driving forces for phase transformations, the kinetics of nucleation and growth, interfacial structures and energies, transformation crystallography, surface reliefs, and, above all, the atomic mechanisms of phase transformations. Phase transformations and microstructural evolution are directly linked to materials processing, properties, and performance, including in extreme environments, of structural metal alloys. Here, aspects of phase transformations and microstructural evolution are highlighted from the atomic to the microscopic scale for ferrous and non-ferrous alloys.

The first two papers explore phase transformations and microstructural evolution in ferrous alloys designed for performance in extreme environments. In the paper entitled "Spinodal Decomposition in Multilayered Fe-Cr System: Kinetic Stasis and Wave Instability" by Maugis et al., thin films of iron $(\mathrm{Fe})$ and chromium $(\mathrm{Cr})$ are used to simulate compositionally modulated microstructures produced by spinodal decomposition and after aging at $500^{\circ} \mathrm{C}$, or microstructural characteristics that may exist in these potential Gen IV fission reactor fuel cladding materials that may lead to deleterious mechanical properties. Fe-Cr compositional profiles are examined with atom probe tomography (APT), and theoretical calculations are performed to provide context with respect to the experimental results. The second paper entitled "Role of Y-Al Oxides During Extended Recovery Process of a Ferritic ODS Alloy" by Capdevila et al. examines the microstructural stability and location

Amy J. Clarke is the guest editor for the Phase Transformations Committee of the TMS Materials Processing \& Manufacturing Division, and coordinator of the topic Phase Transformations and Microstructural Evolution: Part I in this issue. of oxide precipitates in an oxide dispersionstrengthened (ODS) iron-chromium-aluminum (FeCr-Al) alloy during recrystallization. These advanced materials are of interest for possible energy applications requiring high-temperature performance. Titanium (Ti) was found at grain boundaries by APT, which may influence interfacial migration during recrystallization and have implications with respect to processing variations.

The next two papers delve into the physical metallurgy of steels and the mechanical properties generated by phase transformations and microstructural evolution. In the paper entitled "Phase Separation in Lean Grade Duplex Stainless Steel 2101" by Garfinkel et al., the microstructural and mechanical property evolutions produced by thermal aging are examined for a lean alloy duplex stainless steel (DSS) of potential interest for nuclear power generation applications. APT was used to study phase separation kinetics and G-phase formation, and microstructural and mechanical property comparisons are made with two other DSS alloys. In the paper entitled "Tensile Response of Two Nano-Scale Bainite Composite-Like Structures" by Morales-Rivas et al., the processing and microstructural evolution and resulting mechanical properties of two nano-scale bainitic steels are explored. These nano-scale microstructures, created by conventional processing that contain carbon-enriched retained austenite and bainitic ferrite, are affording unique and promising combinations of strength and ductility for a variety of structural applications.

The final two papers explore phase transformations and microstructural evolution in non-ferrous alloys. The paper entitled "Trace Carbon in Biomedical Beta-Titanium Alloys: Recent Progress" by Zhao et al. reviews the progress made with respect to titanium alloys for biomedical applications, with particular emphasis on the role of carbon (C) on microstructural evolution; directions for future work are also highlighted. The paper entitled "Influence of Dilute Hf Additions on Precipitation and Martensitic Transformations in Ni-Ti-Pd 
Alloys" by Coppa et al. examines the effect of hafnium (Hf) additions on P-phase precipitation and martensitic transformation in a nickel-titaniumpalladium (Ni-Ti-Pd) shape memory alloy for actuator applications. Advanced microstructural characterization reveals that $\mathrm{Hf}$ additions influence the mechanical properties and precipitate growth and coarsening kinetics. The microstructural evolution and characteristics are also found to play a key role in the martensitic transformation and the resulting mechanical properties.

The following papers being published under the topic of Phase Transformations and Microstructural Evolution: Part I provide recent advancements on the subject. To download any of the papers, follow the url http://link.springer.com/journal/11837/67/ 10/page/ 1 to the table of contents page for the October 2015 issue (vol. 67, no. 10).

- "Spinodal Decomposition in Multilayered Fe-Cr System: Kinetic Stasis and Wave Instability," by P. Maugis, Y. Colignon, D. Mangelinck, and K. Hoummada
- "Role of Y-Al Oxides During Extended Recovery Process of a Ferritic ODS Alloy," by C. Capdevila, G. Pimentel, M.M. Aranda, R. Rementeria, K. Dawson, E. Urones-Garrote, G Tatlock, and M.K. Miller

- "Phase Separation in Lean Grade Duplex Stainless Steel 2101," by D.A. Garfinkel, J.D. Poplawsky, W. Guo, G.A. Young, and J.D. Tucker

- "Tensile Response of Two Nano-Scale Bainite Composite-Like Structures," by L. Morales-Rivas, H.-W. Yen, B.-M. Huang, M. Kuntz, F. Caballero, J.-R. Yang, and C. Garcia-Mateo

- "Trace Carbon in Biomedical Beta-Titanium Alloys: Recent Progress," by D. Zhao, T. Ebel, M. Yan, and M. Qian

- "Influence of Dilute Hf Additions on Precipitation and Martensitic Transformations in Ni-TiPd Alloys," by A.C. Coppa, M. Kapoor, B.C. Hornbuckle, M.L. Weaver, R.D. Noebe, and G.B. Thompson 